\title{
IOT ENABLED ORGAN PRESERVATION, MONITORING, AND TRANSPORTATION SYSTEM
}

\author{
Abirami Manisa.S \\ Department of ECE \\ Dr. N.G.P Institute of Technology \\ Coimbatore, Tamil Nadu, India
}

\begin{abstract}
Organs are the most vital source of living. And the need for it has increased in day to day life. Hence, the organs required for transplantation are in greater demand. But, due to the fewer preservation methodologies taken for the organs, the transplantation rate is less. By using this technique of preservation, the organs are maintained in a living state until it is been transplanted hence increasing the preservation time. The predefined medical parametric values of the organ make it user friendly and in addition to it, the real-time monitoring of the functionality of the organs is done, which makes it easier to find if any exceptional errors occur.
\end{abstract}

Keywords-Organ preservation, Perfusion, Real-time monitoring

\section{INTRODUCTION}

Organ transplantation is one of the greatest medical marvels of the twentieth century, which has prolonged and improved the lives of hundreds of thousands of patients.[7] It is the most effective therapy for patients with end-stage disease. A supply of high-quality donor organs is crucial to transplantation procedures; organ preservation has been described as "the supply line for organ transplantation". [1] It allows time for preparation of the recipient, organization of staff and facilities, allocation and transportation of the organ, and laboratory tests.[2],[3].

Every year 500,000 people in India, including kids, die waiting for an organ. This is due to the less organ preservation time taken by the static cold storage method (SCS).[7] This method of preservation and transportation system is most prevalent in India. And the other method called the Machine Perfusion method is rarely used as it is more complex and expensive.

This model is a perfusion system which can preserve a donor heart in a near-normothermic beating state from retrieval until it is transplanted, by maintaining the temperature, pressure, $\mathrm{pH}$ level, humidity of the organ.
In simple, the donor's organs are maintained in a living and functioning state. The warm, oxygenated and nutrientenriched blood is used as perfusate and made to flow through the organ.

It makes the physician note the parameters instant to instant through the monitor and check its working condition. And it is fully automated in such a way that there is no requirement of perfect knowledge to operate it. And when it is manufactured in India, it becomes available to all kinds of people who require it.[1],[2]

\section{PRODUCT BRIEF}

The innovative aspects are that it is the only system available in clinical practice that may preserve a donor heart in a near-normothermic and beating state from retrieval until heart transplantation.

Using this system, it allows the heart to be transported over a longer distance than cold storage and the real-time monitoring about the organ's condition at any instant could also be done. Both of these factors may result in an increased number of hearts suitable for donation.

\section{PROPOSED DESIGN}

The device is a perfusion system that can preserve a donor's heart in a beating state from retrieval until it is transplanted.

- The two main elements of the system are the console and the heart perfusion set, and each has several subunits.

- The console is an electromechanical, portable console with a wireless monitor. It contains an infusion pump and circulatory pump, batteries, display, keypad, gas delivery subsystem, and probes.

- The heart is continuously monitored concerning its physiological parameters such as coronary flow, aortic flow, mixed venous hemoglobin saturation percentage, blood temperature, $\mathrm{pH}$ level, humidity content of the blood and pulmonary artery pressure.

- These are measured with the help of respective sensors. The analog value obtained as output from the 


\section{International Journal of Engineering Applied Sciences and Technology, 2020 \\ Vol. 4, Issue 11, ISSN No. 2455-2143, Pages 202-207 \\ Published Online March 2020 in IJEAST (http://www.ijeast.com)}

various sensors is converted to a digital value by ADC.

- The blood pressure value obtained is sent to the signal conditioning unit to be made readable by the controller.

- The console also provides a docking station for the display screen and storage for maintenance solutions.

- The outer box provided is portable, weightless and is made up of fiber. It is temperature resistant and withstands at any kind of circumstance.

- The console is reusable hardware that contains the components needed to drive (Driver unit), condition (Conditioning unit) and monitor the heart perfusion module, which is part of the heart perfusion set.

- The heart perfusion set contains all of the components that directly contact blood and non-contact components are also used for the heart during heart preservation.

- It is a single-use biocompatible perfusion and monitoring device, which includes the following: Heart perfusion module, which provides the sterile blood circuit and protected environment for the heart in the system. The module communicates wirelessly with the console monitor.

- The heart is kept in the organ chamber of this module.

- Blood collection set, including a blood collection bag, line, clamp, and a cytokine filter set. The blood collection set is used to collect blood from the donor for donor heart perfusion. The blood passes through the cytokine filter into the heart perfusion module reservoir.

- The amount of flow of blood in the organ is to be set and this is achieved by the flow rate sensor.

- The various values of the temperature, pressure, $\mathrm{pH}$, humidity and the flow rate to be maintained are programmed in the controller.

- The normal and average medical parameters in the human body are as follows:

- Temperature: 37 degrees Celsius

- Pressure: $120 / 80 \mathrm{mmHg}$

- $\mathrm{pH}: 7$ (neutral)

- Humidity: Varies according to the atmospheric $\circ$ Condition that prevails

- If there is any deviation in the values, the feedback is given and the appropriate value is set and made to work with the help of pump and driver modules.

- Monitoring accessories package, containing valves to access the heart while it is being perfused on the system.

- The donor heart is connected to the system immediately after explantation and is kept beating until disconnection for transplant. The system maintains heart viability by continuously perfusing the donated heart with warmed, oxygenated blood, supplemented with priming solutions (which maintain the heart during transport while reducing the possibility of inflammatory reactions).

- The system needs nearly 1,000 ml-4,000 ml of blood from the heart donor for the entire process of transportation and until it is transplanted. This blood is filtered and continuously circulated in a closed circuit with the solutions.

- All these activities, data and processes are real-time monitored with the help of the display screen $\&$ pi-camera and could be viewed in any place from the mobile or any other electronic device through IoT.

- Implantation of the heart and subsequent patient care steps after the transplantation follow standard procedures.

\section{Block Diagram}

Organ Transportation Control System (OTCS):

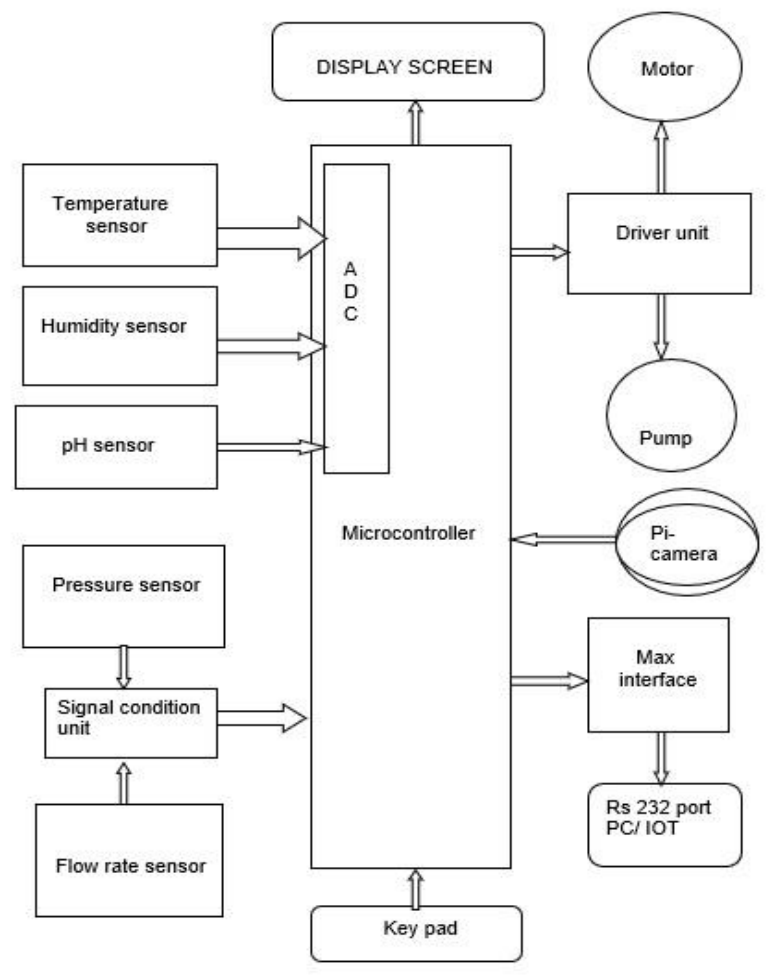

Organ Transportation System (OTS):

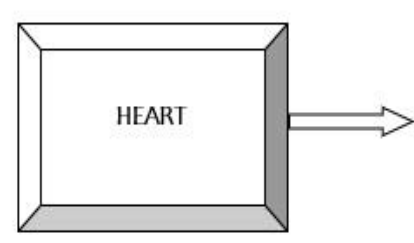

ORGAN BOX

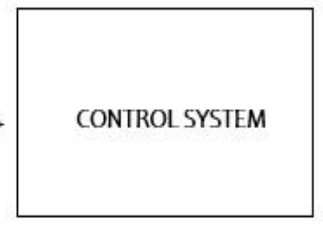

OTCS
${ }^{\star}$ OTCS-Organ Transportation Control System 


\section{INNOVATIVENESS OF THE PROPOSED SOLUTION}

The two main methods of organ preservation are:

- Static cold storage (SCS)

- Machine perfusion[11]

Static cold storage (SCS) offers a simple and effective way to preserve and transport organs and is the most commonly used method.[4] The cost of this is approximately 5,000-15,000INR.[9]

In India, the organ preservation is done only using the static cold storage method. In that, the preservation time for various organs are as follows:

Heart:4 hours

Kidneys:24 hours

Lungs:4 to 6 hours

Liver: 6 to 10 hours

Pancreas: 12 to 18 hours

Intestines:6 to 12 hours [2]

This causes the following issues:

- Variability of packaging materials used

- Biocompatibility of the material that touches the organ

- Difficulty in assessing donor organ function and viability, the inevitability of

Ischemia-Reperfusion Injury (IRI)

- Tissue damage induced by prolonged hypothermic preservation [8]

- Tissue injury due to movement or vibration.

- Potential uneven cooling of organ tissue. [2,3]

So, the method of perfusion is adopted. The perfusion methodology is, making the organ to work by circulating the blood through the various vascular channels. It is of two types

- Hypothermic machine perfusion

- Normothermic machine perfusion

These are not available in India now and it is in the starting stage of implementation only. So, these equipment are taken on a rental basis and it is only by the multispecialty hospitals. Even though these are bought for rental, the cost for one use is approximately 25 lakhs INR and for reusable heart console, it is approximately one and a half crore INR. [10] As it is very much expensive, this device is rarely bought by the patients in India.

Hence, this method is rarely used due to the above issues. All these problems are overcome in our method as follows:
The unique features and advantages of the system are:

- It decreases the amount of damage that occurs to the heart after removal, by reducing the rate of tissue deterioration compared with conventional cold ischemic storage.[10]

- The system allows for hearts to be transported for longer distances in comparison with cold storage.

- The preservation time is tripled for the organs when compared to the SCS system.

- There is no need for manual control and it is fully automated

- No need for prior knowledge about the operation of the device.

- The real-time monitoring and data reporting of the organ can be done.

- When the manufacturing is done in India, the cost could be reduced in further years and in future, it will be made available to all the people who require the organs.

- The overall designed box is portable, weightless, unbreakable and user friendly.

COMPARISON WITH THE EXISTING METHODS AND THE NEW PROPOSAL:

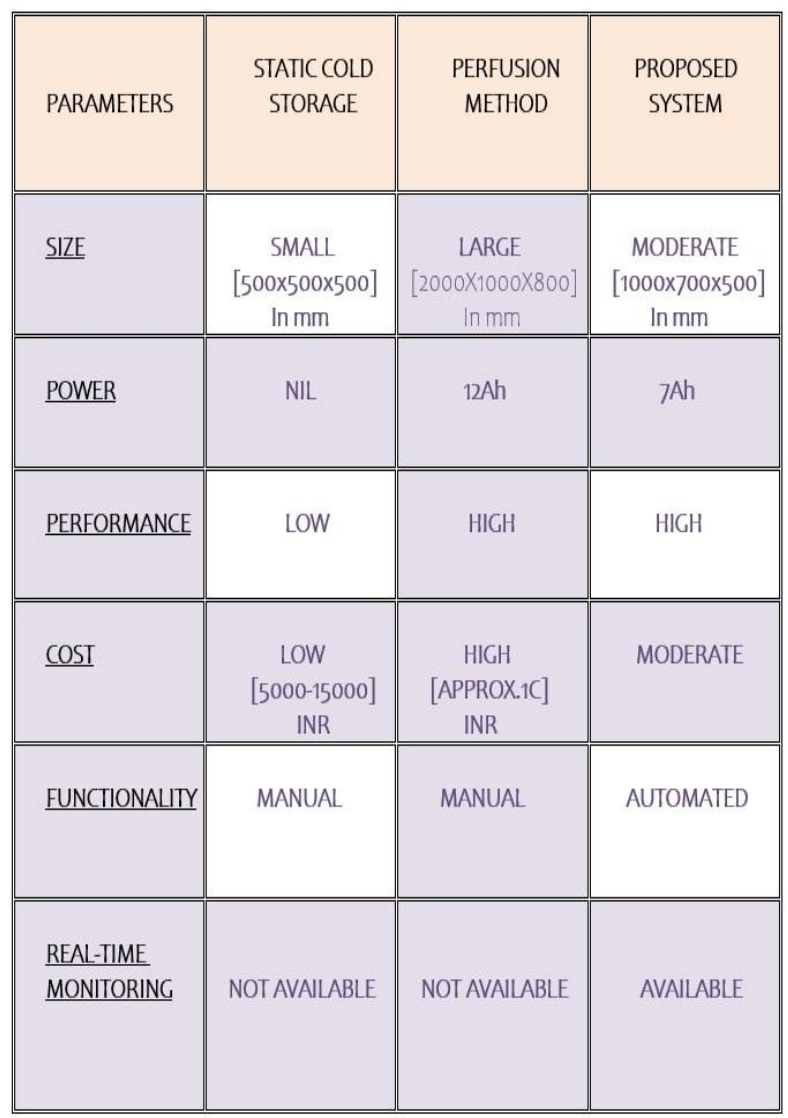




\section{International Journal of Engineering Applied Sciences and Technology, 2020 Vol. 4, Issue 11, ISSN No. 2455-2143, Pages 202-207 \\ Published Online March 2020 in IJEAST (http://www.ijeast.com)}

\section{IMPACT OF THE PROPOSED SOLUTION}

Potential patient impact:

- This method helps in increasing the number of hearts for transplantation, which were previously found reduced due to the complications \& disadvantages of the existing system.

- If this is made available in India, the annual heart transplant activity could potentially increase by $30 \%$ to $40 \%$.

- Increasing the number of donor's hearts would reduce the average waiting time for patients.

- It may also reduce hospital admission rates for decompensation (functional deterioration of the heart), and waiting list mortality.[12]

- The system offers improved outcomes through a reduction in primary graft dysfunction.

- The system has the potential to expand the number of suitable donors, increase the likelihood of heart transplantation, decrease waiting times and potentially reduce mortality rates of people on the waiting list. [12]

Potential system impact:

- In increasing the range of donor hearts available, the system could increase the number of heart transplants.

- This could affect staffing and theatre time (as the system needs more team members present for retrieval), bed usage and post-transplant follow-up.

- These factors may have an impact on the workforce, costs as well as on other services that may be displaced because of the urgent nature of heart transplantation.[9]

- The use of the system has the potential for cost savings by allowing more hearts to become available and reducing overall waiting times, thus limiting prolonged and recurrent hospital admissions associated with heart failure and in-hospital waits.[12]

\section{CONCLUSION}

Thus, from the above explanations and comparisons, this system could save a lot of people who require organs. The versatility in the system and the real-time monitoring of the system makes it more convenient to use and monitor the organ conditions at ease. And this would improve the efficiency of the transportation of organs in the future.

\section{ACKNOWLEDGMENT}

The Author is indebted to various persons for numerous perceptive comments of various drafts of the manuscript and bringing to my attention gaps in my knowledge and holes in my logic.

\section{REFERENCES}

1. Southard J, Belzer F. (1995) “Organ preservation”. Annu Rev Med; (pp 46:235-47).

2. Guibert EE, Petrenko AY, Balaban CL, Somov AY, Rodriguez J V, Fuller BJ. (2011) “Organ preservation: current concepts and new strategies for the next decade". Transfus Med Hemother;(pp 12542).

3. Catena F, Coccolini F, Montori G, Vallicelli C, Amaduzzi A, Ercolani G, et al. (2013) "Kidney preservation: a review of present and future perspective". Transplant Proc;(pp 45: 3170-7).

4. Liu WP, Humphries AL, Russell R, Stoddard LD, Moretz WH, Moretz WH. (1971) "48-hour storage of canine kidneys after brief perfusion with Collins' solution". Ann Surg; (pp 173: 748-57).

5. Michel S.G, LaMuraglia II G.M, Madariaga M.L.L, Anderson Lisa M. (2015) "Innovative cold storage of donor organs using the Paragonix Sherpa Pak TM devices" Heart Lung Vessel.; (pp 7(3): 246-255).

6. Shroff S. (2019) "Twenty-five years of transplantation law in India - Progress and the way forward". Indian J Transplant; (pp 13:151-3).

7. Srivastava A, Mani A.(2018) "Deceased organ donation and transplantation in India: Promises and challenges".; (pp 66:316-22).

8. Taylor MJ, Baicu SC. (2010)" Current state of hypothermic machine perfusion preservation of organs: the clinical perspective". Cryobiology. (pp 60(suppl 1):20-35)

9. Jahania M S, Sanchez J A, Narayan P, Lasley R D, Mentzer R M Jr(1999)." Heart preservation for transplantation: principles and strategies". Ann Thorac Surg. ;(pp 68:983-983).

10. Belzer FO, Southard JH.(1988)" Principles of solidorgan preservation by cold storage". Transpl (pp 45(4): 673-76)

11. Hafez T, Fuller B. (2006) "Applications: Organ preservation for transplantation". In: Baust JG, editor. Advances in Biopreservation. vol 9. Owego: Cell Preservation Services; (pp. 197-270)

12. Hamilton D (2012)." A history of organ transplantation". University of Pittsburgh Press, Pittsburgh

13. https://www.notto.gov.in

14. https://www.narayanahealth.org/blog/kidneytransplants-in-india/

15. https://www.transmedics.com/patients-and-families/ 
16. https://timesofindia.indiatimes.com/city/bengaluru/H eart-comes-for-free-but-transplant-cost-hitspatients/articleshow/51819396.cms

17. https://www.kokilabenhospital.com/departments/cent resofexcellence/centrefor_transplant/organdonation.h tml

18. https://www.nice.org.uk/advice/mib86/resources/ocsheart-system-for-heart-transplant-pdf63499411285189

19. https://www.impactguru.com/blog/organ-donationin-india-infographic 